Proceedings

\title{
Chia Oleogel as a Potential New Ingredient for Healthy Cooked Meat Sausages ${ }^{\dagger}$
}

\author{
José Ángel Pérez-Álvarez 1,* , Alba Roldán-Verdú ${ }^{1}$, Asunción Martínez-Mayoral ${ }^{2}$, Estrella Sayas-Barberá ${ }^{1}$, \\ Casilda Navarro-Rodríguez de Vera ${ }^{1}$, Manuel Viuda-Martos ${ }^{1}$ and Juana Fernández-Lopez ${ }^{1}$
}

Citation: Pérez-Alvarez, J.A.; Roldán-Verdú, A.; Martínez-

Mayoral, A.; Sayas-Barberá, E.;

Navarro-Rodriguez de Vera, C.; Viuda-Martos, M.; Fernández-López, J. Chia Oleogel as a Potential New Ingredient for Healthy Cooked Meat Sausages. Proceedings 2021, 70, 76 . https://doi.org/10.3390/

foods_2020-07701

\section{Published: 10 November 2020}

Publisher's Note: MDPI stays neutral with regard to jurisdictional claims in published maps and institutional affiliations.

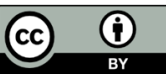

Copyright: $₫ 2020$ by the authors. Licensee MDPI, Basel, Switzerland. This article is an open access article distributed under the terms and conditions of the Creative Commons Attribution (CC BY) license (http://creativecommons.org/licenses/by/4.0/).
1 IPOA Research Group, Agro-Food Technology Department, Higher Polytechnic School of Orihuela, Miguel Hernández University, Orihuela C.P.03312, Alicante, Spain; alba.roldan@goumh.umh.es (A.R.-V.) estrella.sayas@umh.es (E.S.-B.); casilda.navarro@umh.es (C.N.-R.d.V.); mviuda@umh.es (M.V.-M.); j.fernandez@umh.es (J.F.-L.)

2 SORT Research Group, Centro de Investigación Operativa, Universidad Miguel Hernández de Elche, Elche, C.P. 03302 Alicante, Spain; asun.mayoral@umh.es

* Correspondence: ja.perez@umh.es; Tel.:+34-966749739

+ Presented at the 1st International Electronic Conference on Food Science and Functional Foods, 10-25 November 2020; Available online: https://foods_2020.sciforum.net/.

\begin{abstract}
Meat products reformulation is very complicated since the "charcuterie" is more than a technology. The addition of new ingredients is not an easy task; therefore, preliminary assays are carried out to determine their feasibility. Oleogels are "new ingredients" used to mimic fats and/or modify the fatty acids profile. To evaluate the chia oleogel (COG) feasibility in Frankfurt-type cooked sausages (FTCS) processing, several physical and physicochemical parameters, CIELAB color space, 2-Thiobarbituric acid reactive substances (TBARS), moisture, fat, $\mathrm{pH}$, water activity $(\mathrm{Aw})$, and residual nitrite level (RNL), were determined. In a traditional FTCS formula, the COG was used to replace pork back fat (substitution level $0 \%, 25 \%, 50 \%$, and 75\%). In FTCS, RNL were not detected in COG samples. The 75\% substitution with COG increased moisture content. COG addition increased $\mathrm{pH}$. For Aw, COG addition decreased their values in FTCS. The $50 \%$ and $75 \%$ of COG substitution increased TBA values. FTCS fat content for COG-added samples showed values between 22.35 and 23.85 ( $\mathrm{g}$ fat/100 g). Thus, the use of chia oleogels is feasible in an industrial process and can be a good source to reduce nitrite residual level.
\end{abstract}

Keywords: chia mucilage; chia oil; TBA; healthy meat products; oleogels

\section{Introduction}

The COVID-19 pandemic is a very important and complicated challenge since it is forcing many food industries to reformulate their products to meet consumer needs in purchasing healthy foods [1]. Since 2015, the U.S. Department of Health and Human Services and U.S. Department of Agriculture [2] establish that a healthy eating pattern should limit daily consumption of saturated fats to less than $10 \%$ of calories. However, the addition of polyunsaturated fatty acid and oils did not have good success for its technological and sensorial problems in many foods. In the case of meat products, this becomes more complicated since the charcuterie tradition must be combined with science, technology, gastronomy, and economics, among others, to offer a new product or innovate an existing, healthier one. The incorporation of new ingredients in foods and especially in meat products is not an easy task [3], therefore, preliminary tests are carried out to see their technological viability through simple control parameters (mainly $\mathrm{pH}$, water activity (Aw), 2Thiobarbituric acid reactive substances assay (TBARS), and color). In cooked meat products (Frankfurt sausage, mortadella and other), animal fat makes significant functional and sensory contributions to processed meat products [4]. Several years ago, animal fat 
substitution represented a significant challenge for the meat industry. In this way Ospina$\mathrm{E}$ and coworkers [5] developed a chemically modified fat with a healthy profile and similar technological properties to pork fat to replace it. One of the last methods used to reduce animal fats is the application of oleogels [6], since they can be the feasible way to develop healthy meats. Oleogels are developed using several types of polysaccharides (flour, mucilage, gums, etc.) and vegetable oils with high levels of omega-3 fatty acids (chia oil, nut oil, linseed oil, among others). Oleogels can be considered functional ingredients with solid-like properties similar to those of animal fat [7].

Oleogels are "new ingredients" that are used to replace fats in food, but also have the ability to mimic fats and/or modify the profile of fatty acids ("healthier fats") in the meat product, thus reducing, the "bad image" that this type of food has [8]. Several types of oleogels have been used as fat replacement in meat products, but no references about the egg white addition in the oleogels (as emulsifier enhancer) has been found.

The aim of this study was to evaluate the feasibility to use chia mucilage-egg whitebased oleogels (CMEWO) in the Frankfurter-type cooked sausages (FTCS) process and estimate the influence upon industrial physicochemical parameters.

\section{Materials and Methods}

FTCS sausage manufacture: A traditional Frankfurt-type cooked sausage industrial formula ( $60 \%$ lean pork meat, $40 \%$ pork backfat, $15.0 \%$ ice, $3.0 \%$ commercial hydrolyzed quinoa (NATURQUINOA ${ }^{\mathrm{TM}}$ ), $1.8 \%$ sea salt, $100 \mathrm{mg} / \mathrm{kg}$ sodium nitrite, $300 \mathrm{mg} / \mathrm{kg}$ phosphates, and $500 \mathrm{mg} / \mathrm{kg}$ sodium ascorbate) was applied (this formula is considered as control). CMEWO formula was fresh egg white (58\%), water (22.5\%), chia (Salvia hispanica L.) oil $(15.5 \%)$, and chia mucilage $(4.00 \%)$. This oleogel was used to substitute, partially, pork backfat concentration. CMEWO replaced pork back fat at the following range: $0 \%, 25 \%$, $50 \%$, and $75 \%$. All ingredients were food grade and were purchased from a local supplier. Sausages were elaborated in the pilot plant facilities of Miguel Hernandez University.

Proximate composition (moisture and fat) was determined by AOAC (2016) methods [9]. CIELAB (1976) color parameters, lightness $\left(L^{*}\right)$, red/green $(+/-)$ co-ordinate $(a)^{*}$, yellow/blue $(+/-)$ co-ordinate $\left(\mathrm{b}^{*}\right)$ were measured using a spectrophotocolorimeter Minolta CM Minolta CM-700 (Minolta Camera Co., Osaka, Japan), using D65 as illuminant and $10^{\circ}$ as standard observer. Psycophysical magnitudes, chroma $\left(\mathrm{C}^{*}\right)$ and hue $\left(\mathrm{H}^{*}\right)$, and color differences $\left(\Delta \mathrm{E}^{*}\right)$ were calculated as: $\mathrm{C}^{*}=\left(\mathrm{a}^{* 2}+\mathrm{b}^{* 2}\right)^{1 / 2}, \mathrm{H}^{*}=\tan ^{-1}\left(\mathrm{~b}^{*} / \mathrm{a}^{*}\right)$, and $\Delta \mathrm{E}^{*}=\left(\Delta \mathrm{L}^{* 2}+\right.$ $\left.\Delta \mathrm{a}^{* 2}+\Delta \mathrm{b}^{* 2}\right)^{1 / 2}$. Guidelines for meat color evaluation were followed [10] and Sanchez-Zapata recommendations [11] to determine infinite solid (product thickness) and background was used. The $\mathrm{pH}$ of the sausages was measured directly using a Hach puncture electrode probe (5233) connected to a $\mathrm{pH}$-meter (model SensIONTM $+\mathrm{pH}$, Hach-Lange S.L.U., Vésenaz, Switzerland). The measurement was taken three times, changing the place of electrode insertion. The water activity (Aw) was measured at $25^{\circ} \mathrm{C}$ using an electric hygrometer NOVASINA TH200 (Novasina; Axair Ltd., Pfaeffikon, Switzerland). All sample analyses were undertaken in triplicate, except for color measurements in which nine measurements, from each sample, were taken. Residual nitrite level (mg NaNO$/ 2 \mathrm{~kg}$ sample) was determined in agreement with ISO/DIS 2918 standards [12]. Lipid oxidation was assessed in triplicate by the 2-Thiobarbituric acid (TBA) method following the recommendations of Rosmini and co-workers [13]. TBARS values were calculated from a standard curve of malonaldehyde (MA) and expressed as mg MAD $/ \mathrm{kg}$ sample.

A one-way ANOVA was used to evaluate the influence of CMEWO concentration (levels: $0 \%, 25 \%, 50 \%$, and $75 \%$ ). When differences between levels were found, the Tukey's test was applied. The three-elaboration process was undertaken on three different days.

\section{Results}

Table 1 shows the residual nitrite levels, fat content and lipid oxidation (TBARS values) in frankfurter-like sausages with different levels of fat substitution. 
Frankfurt-type sausages are cured and cooked meat products, which means that they have nitrate/nitrite in their formulation. The amount in which they can be added is subject to official regulation [14] because although they have important desirable effects in several aspects of meat products processing and development (mainly color fixation, fat oxidation, flavor, and microbiological safety) [15], their application concerns a potential risk of the formation of carcinogenic, teratogenic, and mutagenic nitroso compounds [16], leading to a trend towards their decrease. As soon as nitrite is added to meat batter, it is reduced to nitric acid to react with myoglobin and other active compounds to develop all the positive actions that have been previously described. Residual nitrite levels in samples added with CMEWO were not detected which means that there is no nitrite available to convert in potential risky substances for health.

The fat content in control, 50\% and 75\% fat replacement with CMEWO did not show statistical differences $(p>0.05)$ with values ranging between 22.35 and 23.85 (g fat/100 g sample in dry-basis); samples with $25 \%$ substitution level showed the lowest fat content. Control samples and samples with $25 \%$ substitution level showed similar TBARS values $(p>0.05)$. Samples with higher substitution levels (50\% and $75 \%)$ showed higher TBARS values $(p<0.05)$ without differences between them. It must be taken into account that samples in which CNEWO has been added should have a lipid profile with higher amount in unsaturated fatty acids than control sausages, in accordance with the composition of chia oil used for the elaboration of this oleogel. In view of that, these samples would be more susceptible to lipid oxidation (higher TBARS values), as was observed. In the case of samples with $25 \%$ substitution level this effect was not shown mainly due to its lower fat content.

Table 1. Residual nitrite level, fat content and lipid oxidation as 2-Thiobarbituric acid rective susbstances(TBARS values) of Frankfurt-type sausages with different level of fat replacement by chia-mucilage egg white-based oleogels (CMEWO).

\begin{tabular}{cccc}
\hline CMEWO \% & Residual Nitrite Level (mg/kg) & $\begin{array}{c}\text { Fat } \\
(\mathbf{g} / \mathbf{1 0 0} \mathbf{~ g})\end{array}$ & $\begin{array}{c}\text { TBARS } \\
(\mathbf{m g ~ M A} / \mathbf{k g})\end{array}$ \\
\hline Control & $35.12 \pm 5.05$ & $22.35 \pm 0.45 \mathrm{a}$ & $0.36 \pm 0.06 \mathrm{~b}$ \\
25 & ND & $20.75 \pm 0.18 \mathrm{~b}$ & $0.36 \pm 0.01 \mathrm{~b}$ \\
50 & ND & $23.45 \pm 0.68 \mathrm{a}$ & $0.58 \pm 0.04 \mathrm{a}$ \\
75 & ND & $23.85 \pm 0.68 \mathrm{a}$ & $0.58 \pm 0.05 \mathrm{a}$ \\
\hline
\end{tabular}

$\mathrm{a}, \mathrm{b}$ Similar values in the same column indicate not significant differences $(p>0.05)$.

Table 2 shows $\mathrm{pH}$, water activity and moisture content in frankfurter-like sausages with different levels of fat substitution. The addition of CMEWO increased moisture content $(p<0.05)$, but samples with the highest level of substitution showed values similar to control $(p>0.05)$. The addition of CMEWO increased the $\mathrm{pH}$ values; the higher the fat substitution level, the higher $\mathrm{pH}$ value. The addition of CMEWO reduced the water activity in sausages and this reduction was dependent on the substitution level. $\mathrm{pH}$ and activity water values for all sausages may be considered normal for this type of meat product [17].

Table 2. Moisture content, $\mathrm{pH}$ and water activity (AW) of Frankfurt-type sausages with different level of fat replacement by chia-mucilage egg white-based oleogels (CMEWO).

\begin{tabular}{cccc}
\hline CMEWO \% & Moisture Content $(\mathbf{g} / \mathbf{1 0 0} \mathbf{g})$ & $\mathbf{p H}$ & Aw \\
\hline Control & $69.54 \pm 0.37 \mathrm{c}$ & $5.90 \pm 0.02 \mathrm{~d}$ & $0.984 \pm 0.002 \mathrm{a}$ \\
25 & $70.94 \pm 0.09 \mathrm{~b}$ & $6.01 \pm 0.02 \mathrm{c}$ & $0.980 \pm 0.000 \mathrm{~b}$ \\
50 & $72.01 \pm 0.43 \mathrm{a}$ & $6.11 \pm 0.01 \mathrm{~b}$ & $0.976 \pm 0.001 \mathrm{c}$ \\
75 & $69.56 \pm 0.12 \mathrm{c}$ & $6.25 \pm 0.01 \mathrm{a}$ & $0.969 \pm 0.001 \mathrm{~d}$ \\
\hline
\end{tabular}

a-d Similar values in the same column indicate not significant differences $(p>0.05)$. 
Meat product color is significant to consumer acceptance of products. Color formation in cured meat products involves, basically, the reaction of endogenous pigments in muscle, essentially myoglobin $(\mathrm{Mb})$, with nitric oxide $(\mathrm{NO})$ from added nitrite. The nitrosated and typical red pigment, nitrosomyoglobin $(\mathrm{NOMb})$ is called "cured meat pigment", and it is converted to nitrosohaemochrome by the cooking process. This latter pigment has a pinkish color, which is known to be stable with cooking [18]. Table 3 shows the values of color coordinates, psycophysical magnitudes and color differences in frankfurter-like sausages with different levels of fat substitution. The results indicate that the concentrations of $50 \%$ and $75 \%$ of substitution of animal fat did not present significant differences $(p>0.05)$ between them, if found between them $(p<0.05)$ and the rest of the concentrations studied. The incorporation of the oleogel makes the sausages brighter. Regarding the red-green coordinate $\left(\mathrm{a}^{*}\right)$, it can be seen that the incorporation of the CMEOW decreased the values of this coordinate. Despite finding significant differences, since the values are less than unity, these differences lack practical meaning. It should be mentioned that the incorporation of the oleogel did not affect the red component of the color $(p>$ $0.05)$. Regarding the yellow component of the color, the incorporation of oleogel increased $(p<0.05)$ the values of this coordinate, but it was independent of the added concentration. Similar behavior was found for chroma, being able to indicate that the addition of the oleogel makes the color of the meat product more saturated. Regarding the tone, it did not present significant differences between the different concentrations of oleogel and the control $(p>0.05)$. Regarding the differences in color, the samples with a $50 \%$ and $75 \%$ substitution of fat of animal origin by oleogels did not present significant differences $(p>0.05)$ between these and the rest of the samples. The existing values indicate that these differences are very noticeable to the human eye.

Table 3. Values of the CIELAB color space coordinates (luminosity $\left(\mathrm{L}^{*}\right)$, red/green coordinate $\left(\mathrm{a}^{*}\right)$, yellow/blue coordinate $\left(b^{*}\right)$ ), psychophysical magnitudes (chroma $\left(\mathrm{C}^{*}\right)$ and hue $\left(\mathrm{H}^{*}\right)$ ) and color differences $\left(\Delta \mathrm{E}^{*}\right)$ in Frankfurt-type sausages with different levels of substitution $(0 \%, 25 \%, 50 \%, 75 \%)$ of the animal fat for a chia mucilage-egg white-based oleogels (CMEWO).

\begin{tabular}{ccccccc}
\hline CMEWO \% & $\mathbf{L}^{*}$ & $\mathbf{a}^{*}$ & $\mathbf{b}^{*}$ & $\mathbf{C}^{*}$ & $\mathbf{H}^{*}$ & \multicolumn{1}{c}{$\mathbf{E}^{*}$} \\
\hline Control & $47.76 \pm 1.20 \mathrm{~d}$ & $2.60 \pm 0.40 \mathrm{a}$ & $9.10 \pm 1.68 \mathrm{~b}$ & $9.47 \pm 1.64 \mathrm{~b}$ & $73.67 \pm 2.90 \mathrm{a}$ & - \\
25 & $54.51 \pm 3.20 \mathrm{c}$ & $2.22 \pm 0.29 \mathrm{ab}$ & $12.46 \pm 1.88 \mathrm{a}$ & $11.66 \pm 2.41 \mathrm{ab}$ & $73.85 \pm 3.01 \mathrm{a}$ & $8.80 \pm 0.34 \mathrm{~b}$ \\
50 & $58.45 \pm 2.17 \mathrm{~b}$ & $1.77 \pm 0.24 \mathrm{~b}$ & $13.07 \pm 1.87 \mathrm{a}$ & $13.20 \pm 2.18 \mathrm{a}$ & $75.05 \pm 3.98 \mathrm{a}$ & $10.16 \pm 0.88 \mathrm{a}$ \\
75 & $59.12 \pm 0.03 \mathrm{a}$ & $1.66 \pm 0.20 \mathrm{~b}$ & $13.97 \pm 1.44 \mathrm{a}$ & $13.48 \pm 2.56 \mathrm{a}$ & $73.85 \pm 0.68 \mathrm{a}$ & $10.29 \pm 0.55 \mathrm{a}$ \\
\hline
\end{tabular}

a-d Similar values in the same column indicate not significant differences $(p>0.05)$.

If the color values obtained from CMEOW $\left(\mathrm{L}^{*}: 46.75 \pm 1.50 ; \mathrm{a}^{*}: 2.54 \pm 0.15 ; \mathrm{b}^{*}: 10.79 \pm\right.$ $\left.0.71 ; \mathrm{C}^{*}: 11.09 \pm 0.70 ; \mathrm{H}^{*}: 76.72 \pm 0.98\right)$ were compared with the samples substituted with oleogel at the different percentages $(0 \%, 25 \%, 50 \%$, and $75 \%)$ it can be seen that it has a certain synergy in the luminosity, yellow/blue coordinate $b^{*}$ and in the chroma $\left(\mathrm{C}^{*}\right)$ not so on the coordinates $\mathrm{a}^{*}$ nor the hue $\left(\mathrm{H}^{*}\right)$; in this case a decrease in their values was observed after its addition to the meat products.

\section{Conclusions}

The use of chia mucilage-egg white-chia oil oleogels is feasible in the cured-cooked sausage industrial processing. Water activity was reduced, and $\mathrm{pH}$ increased in all samples in which CMEWO was added. Fat content was similar to control in samples with $50 \%$ and $75 \%$ pork backfat replacement although showed a higher susceptibility to lipid oxidation. Residual nitrite levels were not detected in all samples in which CMEWO was added. Thus, the use of chia oleogels is feasible in an industrial process and can be a good source to reduce nitrite residual level. 
Author Contributions: Conceptualization, J.Á.P.-Á. and J.F.-L.; methodology, J.F.-L., M.V.-M and E.S.-B.; formal analysis, A.R.-V. and C.N.-R.d.V.; investigation, M.V.-M. and C.N.-R.d.V.; resources, A.M.-M.; data curation, A.M.-M.; writing-original draft preparation, J.Á.P.-Á. and J.F.-L.; writing-review and editing, M.V.-M.; visualization, E.S.-B..; supervision, J.Á.P.-Á.; project administration, E.S.-B.; funding acquisition, J.Á.P.-Á. All authors have read and agreed to the published version of the manuscript.

Funding: This work was supported by FEDER/Ministry of Science and Innovation (MCI-Spain), State Research Agency (AEI) project number "AGL2016-75687-C2-2-R (MCI/AEI/FEDER/UE)". IPOA researchers are members of the HealthyMeat network, funded by CYTED (ref. 119RT0568).

Institutional Review Board Statement: None studies in human were made, this is an analytical research

Informed Consent Statement: None studies in human were made, this is an analytical research

Data Availability Statement: this statement if the study did not report any data. None date are reported.

Acknowledgments: The authors really appreciate the collaboration of students Raquel LucasGonzález and Carmen María Botella-Martínez in the analysis of several samples.

Conflicts of Interest: The authors declare no conflict of interest.

\section{References}

1. Galindo-Espinosa, J.; Castillo-Borja, A.R.; Castro-Heredia, C.E.; Viuda-Martos, M.; Pérez-Alvarez, J.A. Innovación en la era COVID-19: Snacks fusión con toque exótico. Tecnifood 2020, 131, 98-101.

2. U.S. Department of Health and Human Services; U.S. Department of Agriculture. In 2015-2020 Dietary guidelines for Americans, 8th ed.; 2015; Available online: https://health.gov/dietaryguidelines/2015/ (accessed on 20 December 2019).

3. Pérez-Alvarez, J.A.; Viuda-Martos, M.; Fernández-López, J. Research, development and innovation in dairy and meat-based foods using valued added compound obtained from Mediterranean fruit by-products. In Green Extraction and Valorization of ByProducts from Food Processing; Barba, J.B., Soto, E.R., Brncic, B., Rodriquez, J.M.L., Eds.; CRC Publisher: Boca Raton, FL, USA, 2020; pp. 243-275.

4. Tarté, R.; Paulusa, J.S.; Acevedo, N.C.; Kenneth, J.; Prusa, K.J.; Lee, S.L. High-oleic and conventional soybean oil oleogels structured with rice bran wax as alternatives to pork fat in mechanically separated chicken-based bologna sausage. LWT 2020, 131, 109659.

5. Ospina, E.J.C.; Cruz, S.A.; Pérez-Alvarez, J.A.; Fernández-López, J. Development of combinations of chemically modified vegetable oils as pork backfat substitutes in sausages formulation. Meat. Sci. 2010, 84, 491-497.

6. Lucas-González, R.; Roldán-Verdu, A.; Sayas-Barberá, E.; Fernández-López, J.; Pérez-Álvarez,J.A.; Viuda-Martos, M. Assessment of emulsion gels formulated with chestnut (Castanea sativa M.) flour and chia (Salvia hispanica L.) oil as partial fat replacers in pork burger formulation. J. Sci. Food Agric. 2020, 100, 1265-1273.

7. Gómez-Estaca, J.; Pintado, T.; Jiménez-Colmenero, F.; Cofrades, S. The effect of household storage and cooking practices on quality attributes of pork burgers formulated with PUFA- and curcumin-loaded oleogels as healthy fat substitutes. LWT 2020, 119, 108909.

8. López-Pedrouso, M.; Lorenzo, J.M.; Gullón, B.; Campagnol, P.C.B.; Franco, D. Novel strategy for developing healthy meat products replacing saturated fat with oleogels. Curr. Opin. Food Sci. 2021, 40, 40-45.

9. AOAC. Association of Official Analytical Chemists. In Official Methods of Analysis Chemists, 20th ed.; AOAC International: Washington, DC, USA, 2016.

10. AMSA. Meat Color Measurement Guidelines; American Meat Science Association: Savoy, IL, USA, 2012.

11. Sánchez-Zapata, E.; Fuentes-Zaragoza, E.; Navarro-Rodríguez de Vera, C.; Sayas, E.; Sendra, E.; Fernández-López, J.; PérezAlvarez, J.A. Effects of tuna pâté thickness and background on CIEL*a*b* color parameters and reflectance spectra. Food Control 2011, 22, 1226-1232.

12. International Organization for Standardization. Meat and Meat Products: Determination of Nitrite Content; ISO/DIS 2918.26; International Standard 2918; Ref. No. ISO 2918; International Organization for Standardization: Geneva, Switzerland.

13. Rosmini, M.R.; Perlo, F.; Pérez-Alvarez, J.A.; Pagán-Moreno, M.J.; Gago-Gago, A.; López-Santoveña, F.; Aranda-Catalá, V. TBA test by an extractive method applied to pâté. Meat Sci. 1996, 42, 103-110.

14. EFSA. EFSA panel on food additives and nutrient sources added to food (ANS); Statement on nitrites in meat products. EFSA J. 2010, 8, 1538. Available online: www.efsa.europa.eu (accessed on 10 February 2020).

15. Andrée, S.; Jira, W.; Schwind, K.H.; Wagner, H.; Schwägele, F. Chemical safety of meat and meat products. Meat Sci. 2010, 86, 38-48.

16. Viuda-Martos, M.; Fernández-López, J.; Sayas-Barbera, E.; Sendra, E.; Navarro, C.; Pérez-Álvarez, J.A. Citrus co-products as technological strategy to reduce residual nitrite content in meat products. J. Food Sci. 2009, 74, R93-R100. 
17. Fernández-López, J.; Lucas-González, R.; Roldán-Verdú, A.; Viuda-Martos, M.; Sayas-Barbera, E.; Ballester-Sánchez, J.; Haros, C.M.; Pérez-Alvarez, J.A. Effects of black quinoa wet-milling coproducts on the quality properties of bologna-type sausages during cold storage. Foods 2020, 9, 274.

18. Sakata, R. Studies on physicochemical characteristics of red pigments in meat products. Anim. Sci. J. 2000, 71, 1-16. 